\title{
Steady and unsteady flow inside a centrifugal pump for two different impellers
}

\author{
Tarek A. Meakhail ${ }^{1,}$, Mohamed Salem ${ }^{1}$, Ibrahim Shafie ${ }^{2}$ \\ ${ }^{1}$ Mechanical Power Engineering Department, Faculty of Energy Engineering, Aswan University, Aswan, Egypt \\ ${ }^{2}$ Faculty of Engineering, Assiut University, Assiut, Egypt
}

\section{Email address:}

Mina_tarek@hotmail.com (T. A. Meakhail)

\section{To cite this article:}

Tarek A. Meakhail, Mohamed Salem, Ibrahim Shafie. Steady and Unsteady Flow inside a Centrifugal Pump for Two Different Impellers. International Journal of Energy and Power Engineering. Vol. 3, No. 2, 2014, pp. 65-76. doi: 10.11648/j.ijepe.20140302.15

\begin{abstract}
Various parameters affect the pump performance. The impeller outlet diameter, the blade angle, the blade number and casing are the most critical. In this study, experimental and numerical investigations are carried out for two impellers different in diameter with the same casing. Numerical simulation of the whole machine (impeller, vaneless diffuser and volute) is performed using CFX-Tascflow commercial code. A frozen rotor simulation model is used for the steady state calculations and the rotor/stator model is used for the unsteady one. The model pump has a design rotation speed $2800 \mathrm{rpm}$ and two impellers with 7 blades (70 $\mathrm{mm}$ and $105 \mathrm{~mm}$ outer diameters). For each pump, the performance measurements are measured and CFD analyses are carried out for different flow rates for steady and unsteady calculations. Finally, a comparison between the CFD and performance measurement is fairly good.
\end{abstract}

Keywords: Centrifugal Pump, Unsteady, Steady, CFD

\section{Introduction}

There has been steady progress in the field of pump flow computations during the past decade. These advances have made it possible for pump designers to carry out analysis of various flow phenomena occurring inside pumps. To improve design of these pumps, a better understanding of the flow of such machines is required.

The flow in centrifugal pumps is exceedingly complex, involving curvature, system rotation, separation, turbulence, unsteadiness and secondary flows. Moreover, the geometry is often asymmetric due to the volute shape. As a result, the relative motion between impeller and volute generates an unstableness which affects not only the overall pump performance, but is also responsible for pressure fluctuations, hydraulic noises and unforeseen hydrodynamic forces. These fluctuations not only generate noise and vibration that cause unacceptable levels of stress and reduce component life due to fatigue, but also introduce unfavorable characteristics of pump performance even at or near the design point. Experimental and numerical approaches contributed to the understanding of the highly complex flow interactions that occur in a centrifugal pump.

Binder et al. [1], Acosta et al. [2], and Stepanoff [3] conducted some of the earliest investigations on impeller forces in centrifugal pumps. Stepanoff proposed a simple empirical model based on impeller geometry, pump head and capacity to estimate the radial resultant forces. Agostinelli et al. [4] extended Stepanoff's model taking to account the effect of specific speed on radial forces. Biheller [5] developed an equation to predict static radial pump forces applicable for a wide range of pump types and operating conditions. Hergt and Krieger [6], Kanki et al. [7] and Chamieh et al. [8] investigated the effects of single and double volute, vaned diffuser casing pumps and the influence of the impeller blades number on the hydrodynamic forces. De Ojeda et al. [9] combined the exit momentum flux and static pressure distributions around the impeller of a double volute pump to evaluate a total resultant radial thrust. A number of authors have treated the problem of the interaction of the impeller and its surroundings experimentally (Inoue and Cumpsty [10], Sideris and Braembussche [11] and Arndt et al. [12, 13]). Meakhail and Park [14], made a detailed PIV measurements and CFD calculations for impeller-diffuservolute interaction for a low speed fan which is similar to the pump. Among others, a contribution to the understanding of the relation between unsteady flow and mechanical problems was the pressure measurements inside 
a high specific speed centrifugal impeller operating in a double spiral volute pump using piezoresistive pressure transducers and a telemetry system (Kaupert et al. [15]).

Ramesha et al. [16] showed that the flow in hydraulic pumps of the radial type, operating at conditions not too far from design point, can be considered as an incompressible potential flow, where the influence of viscosity is restricted to thin boundary layers, wakes and mixing areas. They compared the experimental and the simulated values of the hydraulic efficiencies.

Bao-ling et al. [17] in their study used the Navier-Stokes equations and the Spalart-Allmaras turbulence model, to numerically study and analyze three dimensional turbulent flow fields in centrifugal pump with long-mid-short blade complex impeller. They found that the flow in the passage of the complex impeller is unsymmetrical due to the joint action between the volute and impeller

Raul Barrio et al. [18] studied the unsteady flow behavior near the tongue region of a single-suction volutetype centrifugal pump with a specific speed of 0.47 . The numerical predictions of velocity and pressure, obtained at several reference positions located near the tongue region, showed that the flow pulsation for medium and high flow rates is directly associated to the passage of the blades in front of each reference position. This effect is attributed to the jet-wake pattern and to the secondary flow between the pressure and the suction side of the blades.

In this paper, two impellers are used for performance measurements for the same pump, as well as CFD calculations are performed for frozen rotor and transient simulation.

\section{The Centrifugal Pump}

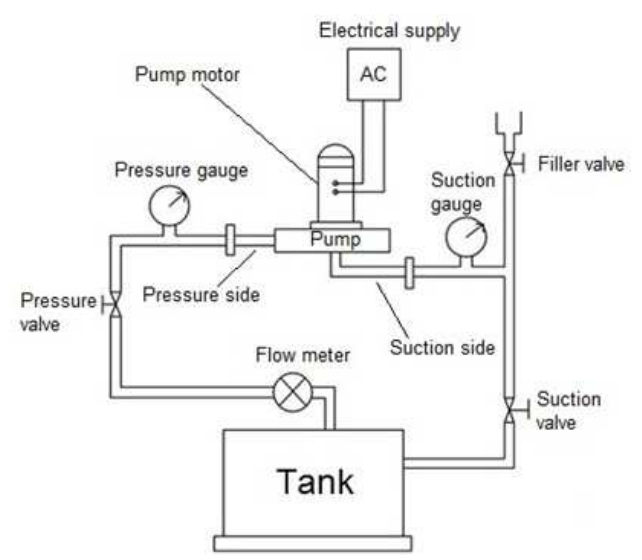

Fig 1. Schematic diagram of the test rig.

The layout of the tested pump is shown in Fig.1. It is a closed circuit rig consists of centrifugal pump, the delivery and suction pipes connected to the tank, flow meter that used to measure the flow rate and controlled by a valve fitted at the end of the delivery pipe. There is also suction valve in-between the tank and pump. The pump is directly coupled to $2800 \mathrm{rpm}$ electric motor. The pump shaft is supported by two ball bearings; one is fixed on the pump pedestal and the other on the left part of the casing. Rubber sealing rings are fitted on both sides of impeller.

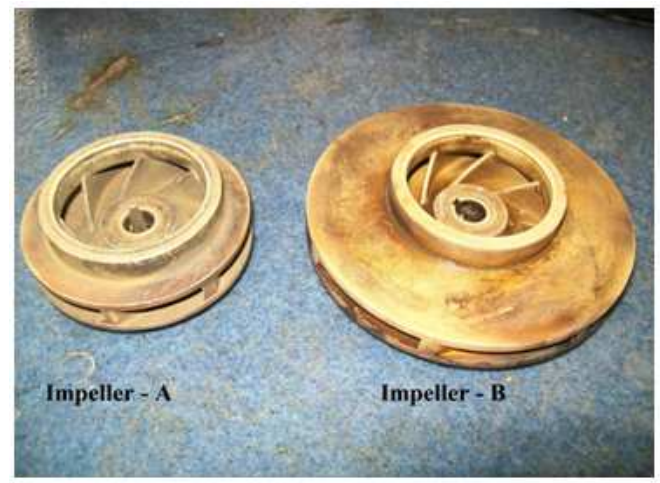

Fig 2. The two impellers used.

Two impellers with different outer diameters as shown in Fig. 2. are used, both impellers are made from fiber and the blades are of the backward type. The outer diameters of the two impellers are $70 \mathrm{~mm}$ and $105 \mathrm{~mm}$, respectively. Both impellers consist of 7 blades $(Z=7)$. Table 1 shows the specifications for the two impellers.

Table 1. Specifications of the pump impellers.

\begin{tabular}{llll}
\hline Description & Parameter & Impeller - A & Impeller - B \\
\hline Number of blades & $\mathrm{Z}$ & 7 & 7 \\
Inlet diameter(mm) & $\mathrm{D}_{1}$ & 40 & 45 \\
Outlet diameter $(\mathrm{mm})$ & $\mathrm{D}_{2}$ & 70 & 105 \\
Inlet blade height $(\mathrm{mm})$ & $\mathrm{b}_{1}$ & 8 & 6 \\
Outlet blade height & $\mathrm{b}_{2}$ & 8 & 6 \\
(mm) & $\beta_{1}$ & $45^{\circ}$ & $26^{\circ}$ \\
Inlet blade angle & $\beta_{2}$ & $44^{\circ}$ & $22^{\circ}$ \\
Outlet blade angle & & & \\
\hline
\end{tabular}

The vaneless diffuser is simply consisting of two walls. The radial clearance between the impeller and vaneless diffuser wall is $1 \mathrm{~mm}$. The outlet diameter of the diffuser is $120 \mathrm{~mm}$ for both impellers. The inlet diffuser diameter for pump (A) is $72 \mathrm{~mm}$ and $107 \mathrm{~mm}$ for pump (B). The volute of centrifugal pump is square type with width $22 \mathrm{~mm}$.

\subsection{Numerical Technique}

The commercially available CFD code, CFX-Tascflow [19], is used to perform the steady state numerical simulation of the whole pump. "Frozen rotor" simulation model is used for the steady state calculation the "rotor/stator" model is used for the unsteady calculation. The code solves the Reynolds averaged Navier-Stokes equations in primitive variable form. The effects of turbulence were modeled using the standard $\mathrm{K}-\varepsilon$ turbulence model. To make the simulation time economical, wall function is used to resolve the wall flows.

\subsection{Grid Generation}

A high quality mesh is produced using a single block Hgrid through the main blade and the passage (for both impeller and diffuser) using CFX-Turbogrid software [20]. 
CFX-Tascgrid is used for volute grid generation. This type of grid generation gives better minimum skew angle, which should not be less than $20 \mathrm{deg}$, and better maximum aspect ratio, which should not be more than 100 . The blades are defined by blocking off grid elements. Figure 3 shows the grid system of the present calculation. The total number of grid nodes is around 1,000,000 nodes for the whole pump.

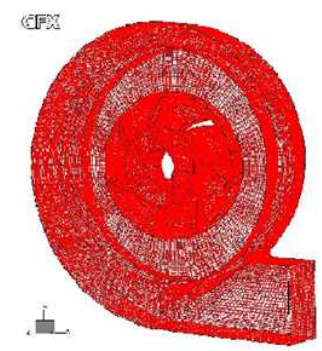

Pump A

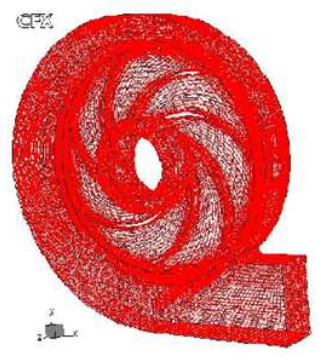

Pump B

\subsection{Boundary Conditions}

The boundary conditions that used for both pumps in the present work are shown in Table 2 . The diffuser and volute are stationary and the impeller is rotating with a rotational speed of $2800 \mathrm{rpm}$. A "frozen rotor" simulation is used first to find the preliminary steady flow field. A "rotorstator" simulation is used to find final unsteady flow, using the steady results as an initial guess. Additionally, the $k-\varepsilon$ turbulence model in TASCflow requires an inlet value for the turbulence intensity ( $\mathrm{Tu}$ ) and the eddy length (L), which can be calculated as the cubic root of the volume of the calculation domain. The computations for the present work run in fully turbulent mode with $\mathrm{Tu}=0.05$ and $\mathrm{L}=0.005$. The time step for the unsteady calculations is 0.0003 second.

Table 2. Boundary conditions.

\begin{tabular}{lllllllll}
\hline & Pump (A) & & \multicolumn{5}{c}{ Pump (B) } \\
& High flow & Med. Flow & Low flow & Zero flow & High flow & Med. flow & Low flow & Zero flow \\
\hline$\dot{m}_{(\mathrm{Kg} / \mathrm{s})}$ & 0.7813 & 0.5263 & 0.2439 & 0 & 1.0345 & 0.67 & 0.3846 & 0 \\
$\mathrm{P}_{\mathrm{o}}(\mathrm{Pa})$ & 106325 & 121325 & 131325 & 136325 & 111325 & 141325 & 161325 & 176325 \\
\hline
\end{tabular}

\section{Results and Discussion}

\subsection{Pressure Distribution at Midspan}

For both pumps the pressure increases gradually along the stream wise direction within the impeller passage and has higher pressure in pressure side than suction side of the impeller blade. However, the pressure developed inside the impeller is not uniform. It is also observed that the static pressure at volute outlet is higher for low flow rates and

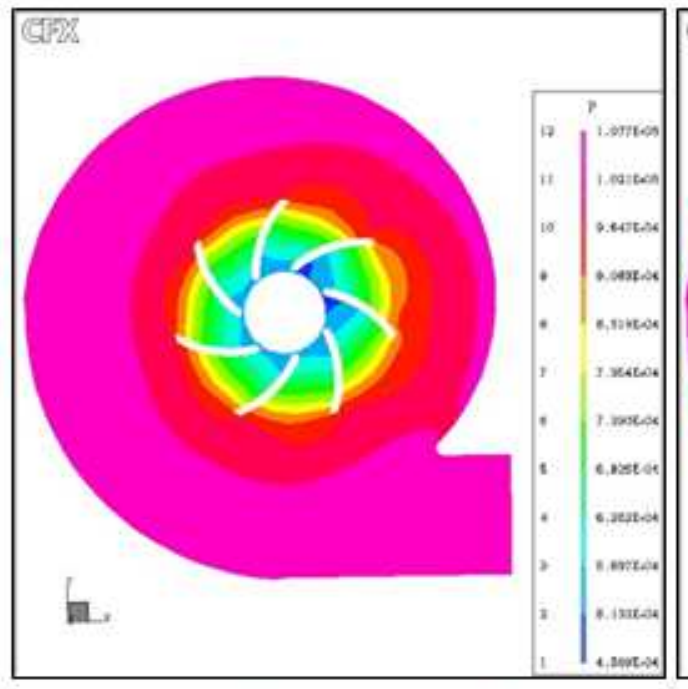

a- Pump (A) high flow rate $(0.78 \mathrm{Kg} / \mathrm{s})$ lower for high flow rates and maximum at zero flow rate. Figure 4 shows the static pressure distribution inside impeller and vaneless diffuser with volute for both pumps at four different flow rates at midspan. Pressure perturbations due to the vortex shedding behind the trailing edge of the blades can be observed also. Outside this band, the pressure field is smoother and it can be observed that the pressure in the impeller is well synchronized. These global pressure variations are due to potential effects.

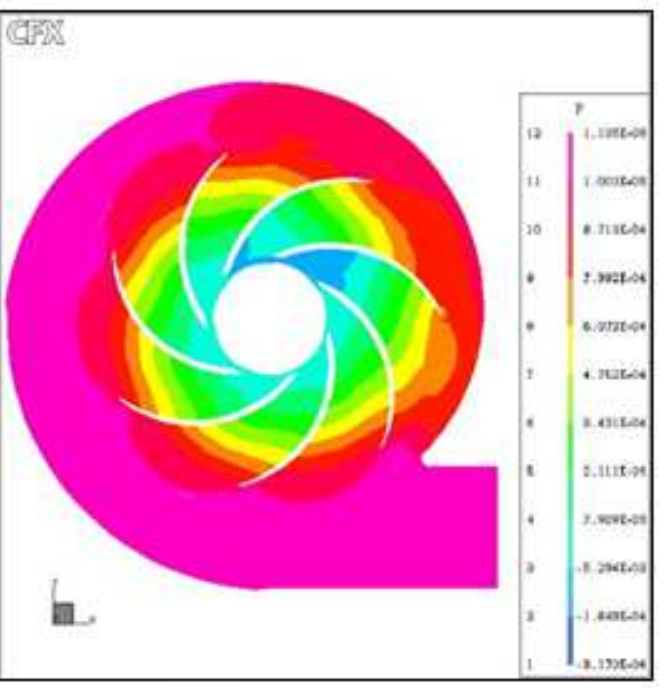

Pump (B) high flow rate $(1.0345 \mathrm{Kg} / \mathrm{s})$ 

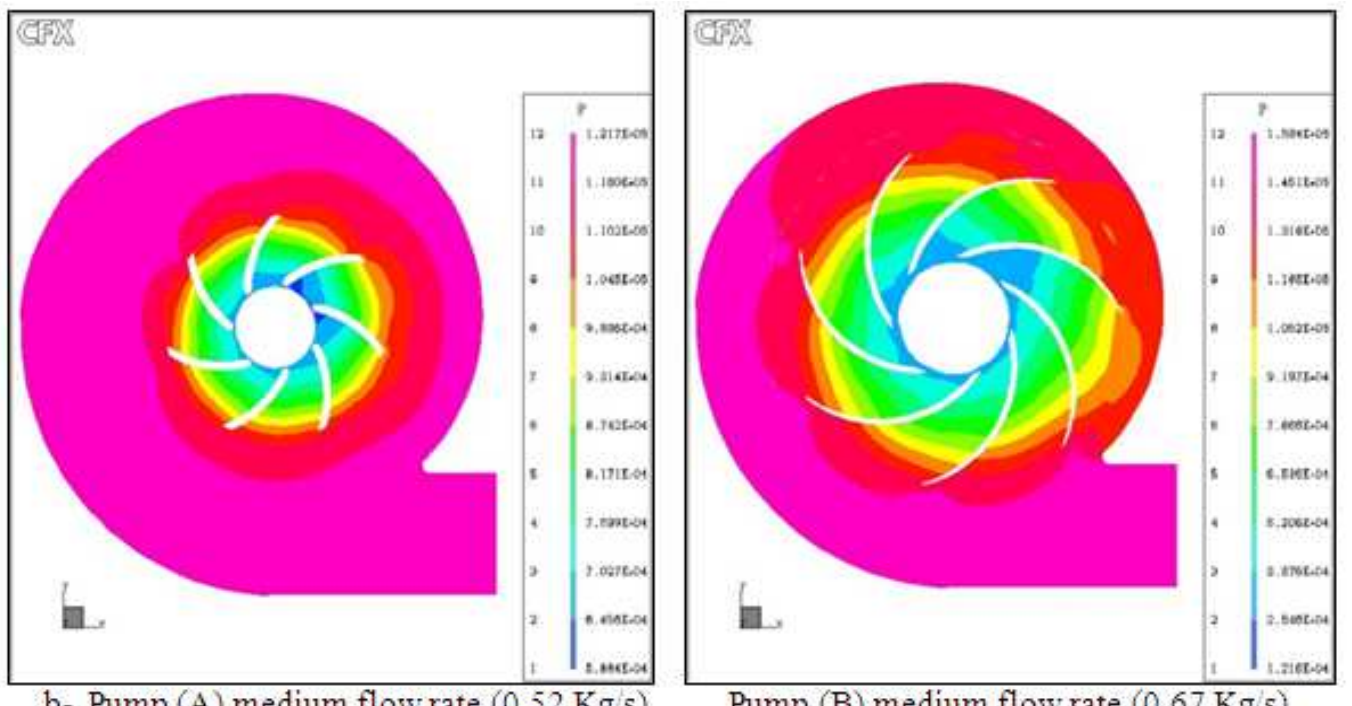

b- Pump (A) medium flow rate $(0.52 \mathrm{Kg}$ s)

Pump (B) medium flow rate $(0.67 \mathrm{Kg} / \mathrm{s})$

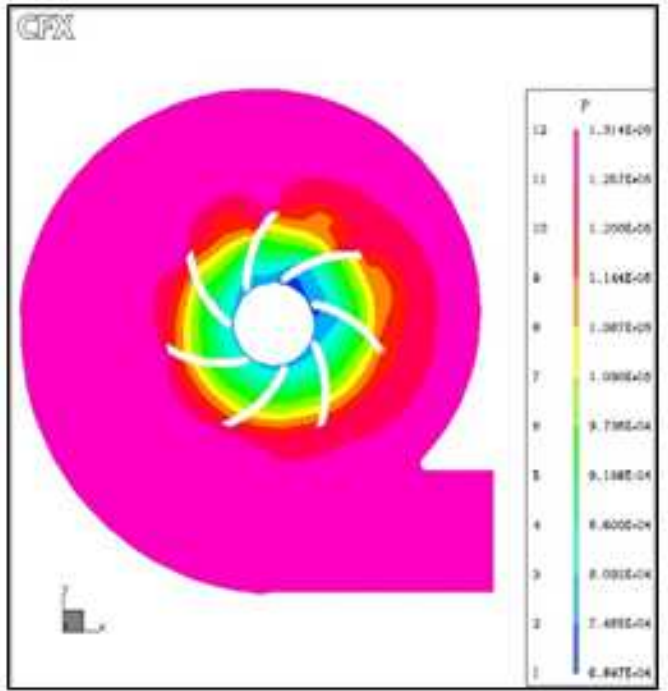

c- Pump (A) low flow rate $(0.24 \mathrm{Kg} / \mathrm{s})$

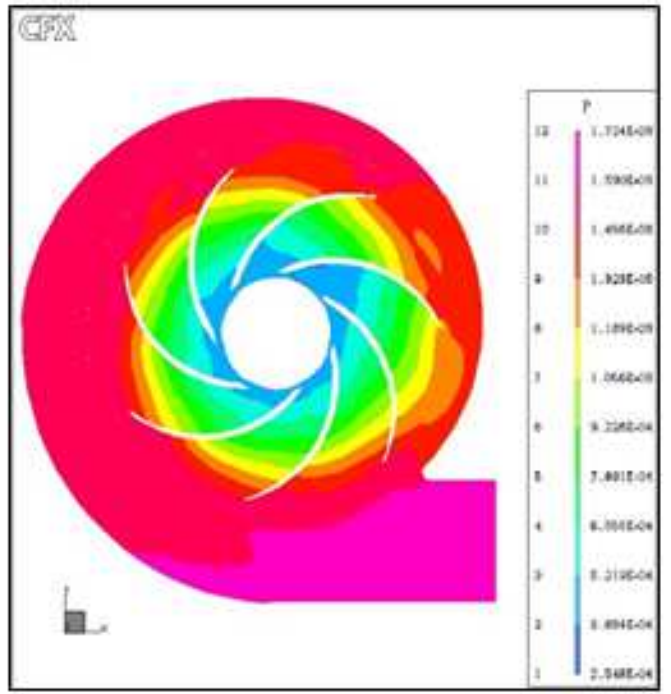

Pump (B) low flow rate $(0.38 \mathrm{Kg} / \mathrm{s})$

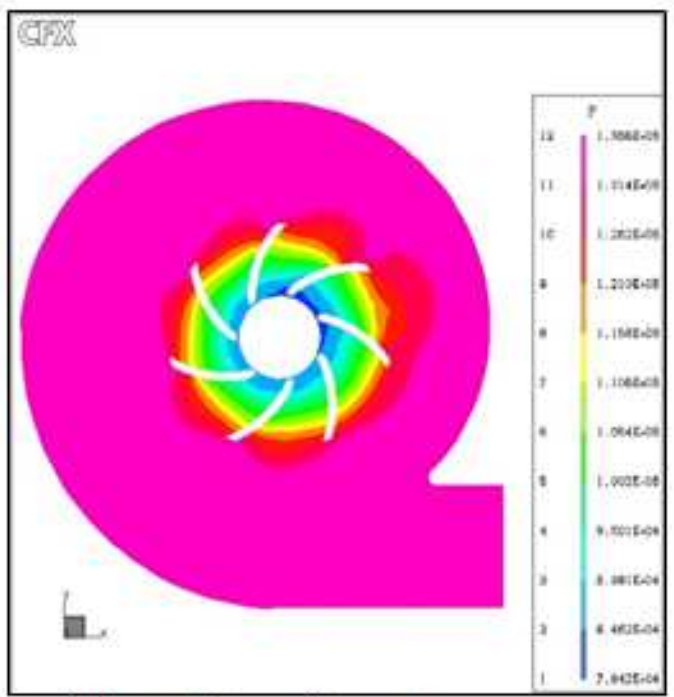

d-Pump (A) zero flow rate

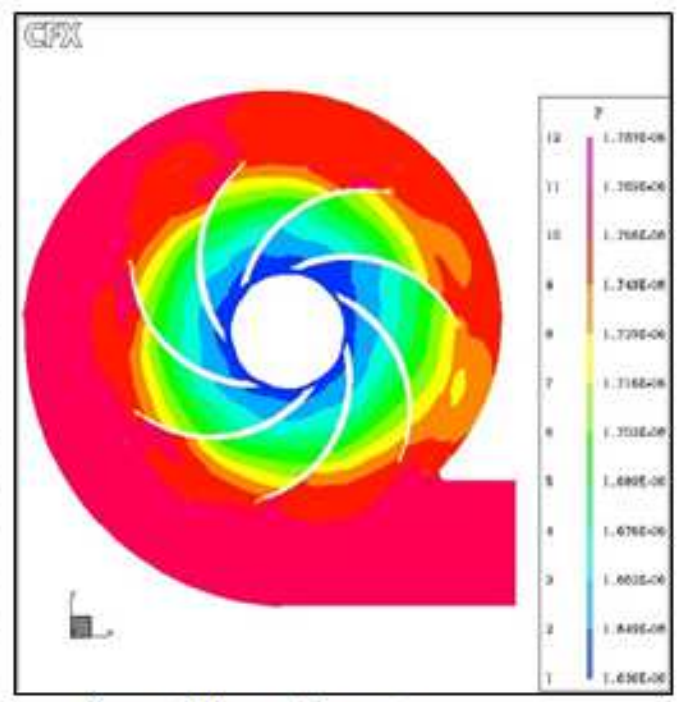

Pump (B) zero flow rate

Fig 4. Pressure distribution at midspan for both pumps. 
The existence of the volute makes the pressure slightly uniform after the impeller. It is found that the maximum pressure value for both pumps is obtained at the outlet duct; it is caused by the energy conversion in the volute which has transformed some of the dynamic pressure into static pressure, The figure also shows that the pressure distribution at different flow rate for pump (A) is more uniform in the volute part than pump (B) and the area of high pressure region in the volute is larger for pump (A).

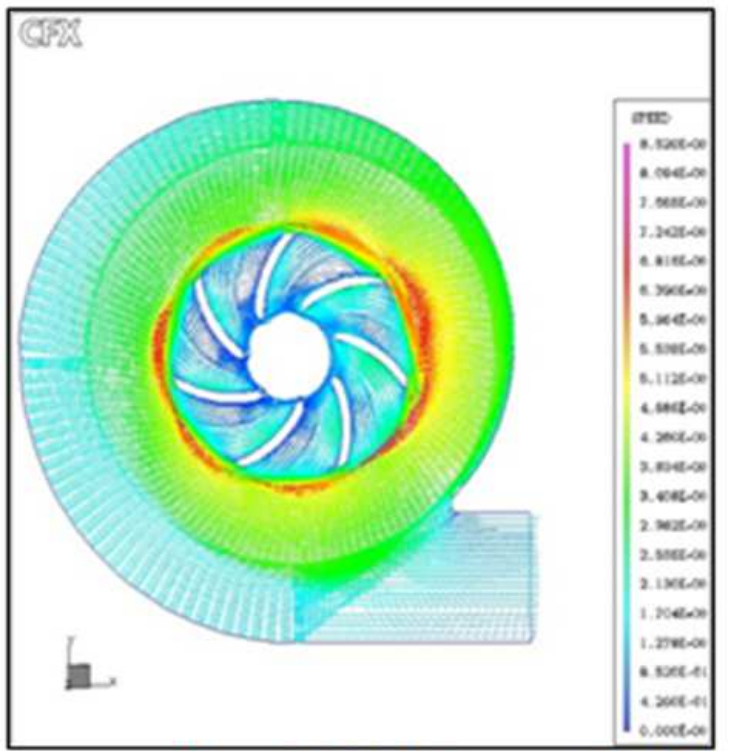

a-Pump (A) high flow rate $(0.78 \mathrm{Kg} / \mathrm{s})$

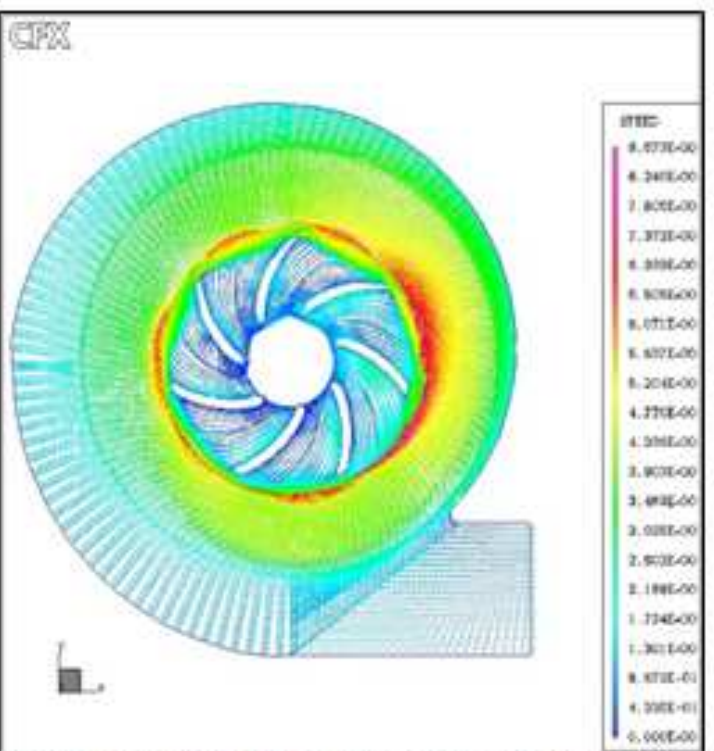

b-Pump (A) medium flow rate $(0.52 \mathrm{Kg} / \mathrm{s})$
For pump (A) the area of the high pressure region in the volute increases with decreasing the flow rate, but this is not the case for pump (B), where the area of the high pressure region in the volute decreases with decreasing the flow rate. The difference in pressure distribution between the two pumps because the vaneless space between the impeller exit and volute inlet is larger for pump (A).

\subsection{Velocity Vectors at Midspan}
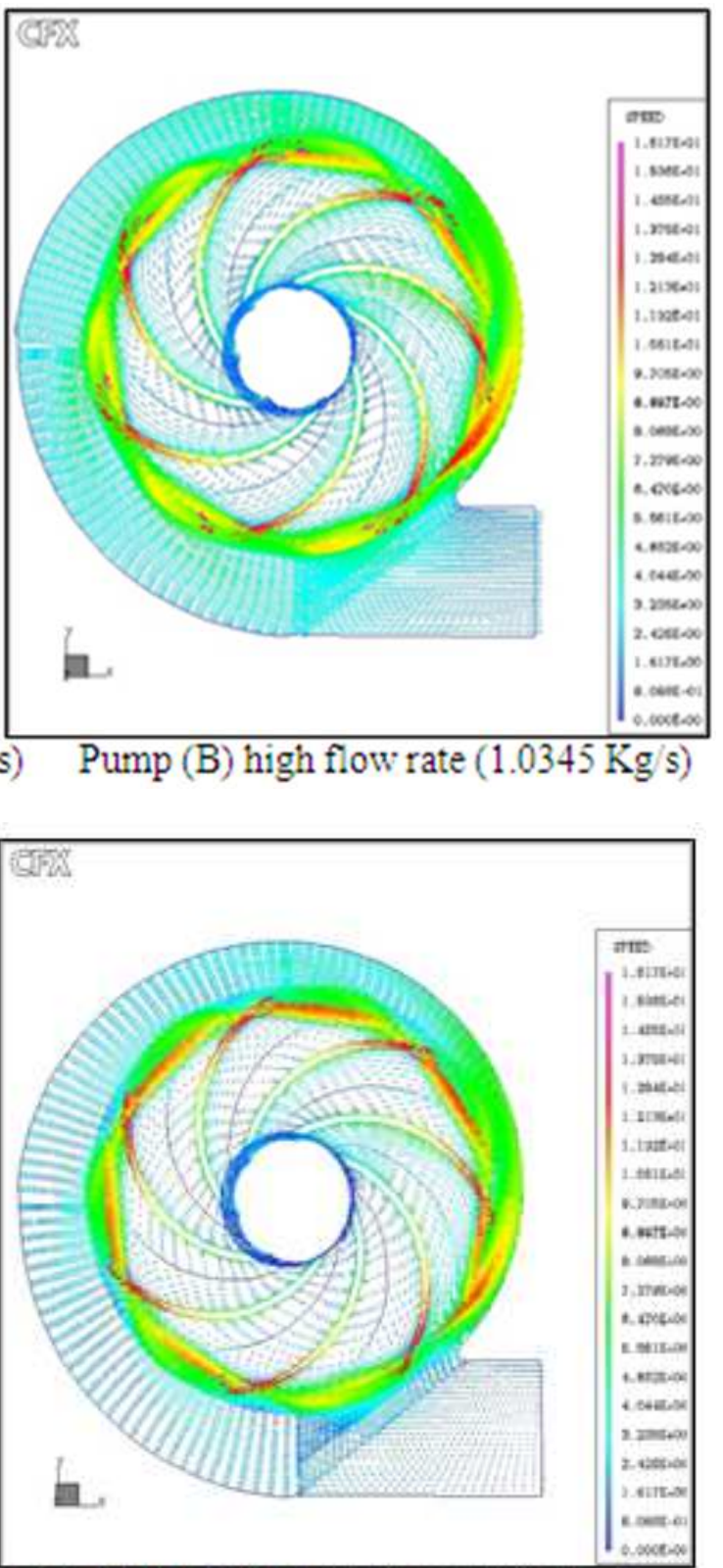

Pump (B) medium flow rate $(0.67 \mathrm{Kg} / \mathrm{s})$ 


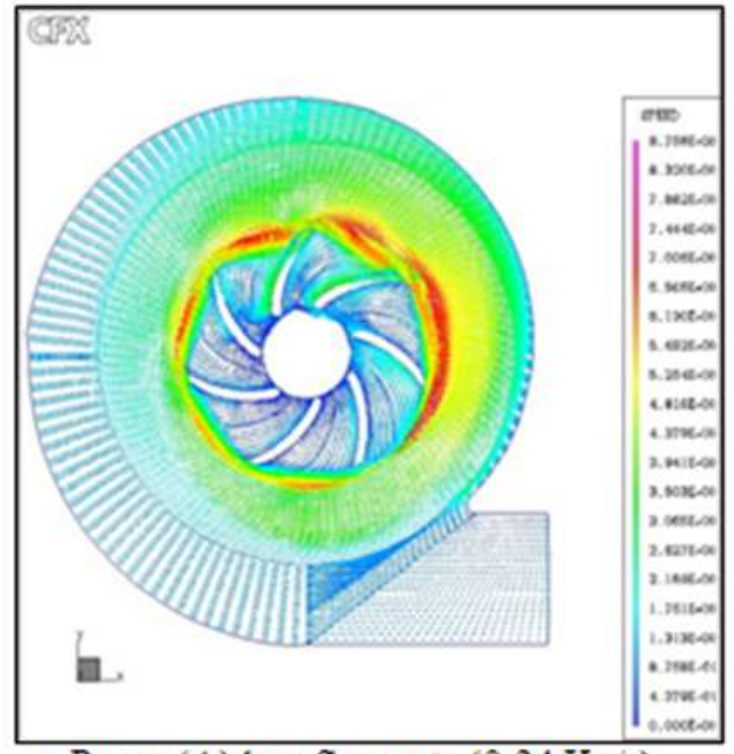

c-Pump (A) low flow rate $(0.24 \mathrm{Kg} / \mathrm{s})$

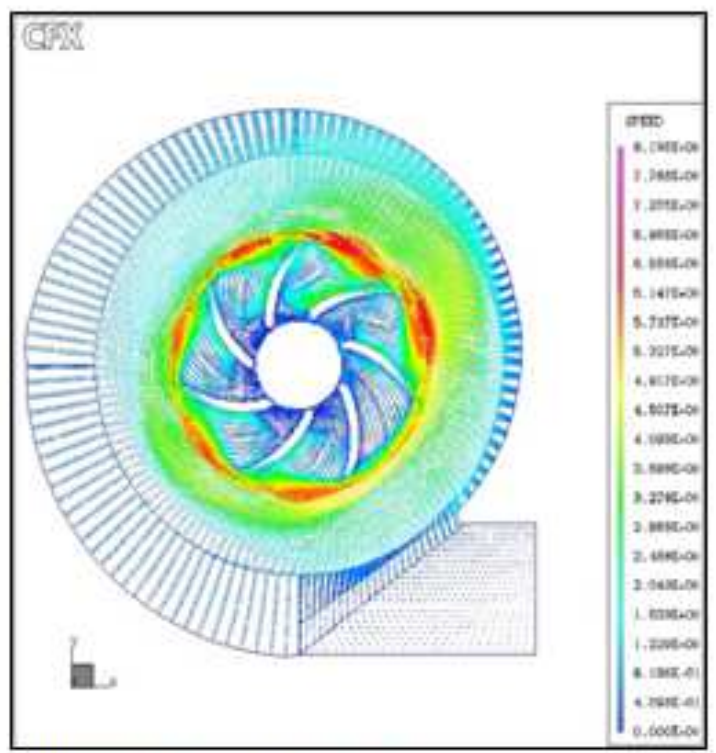

d-Pump (A) zero flow rate

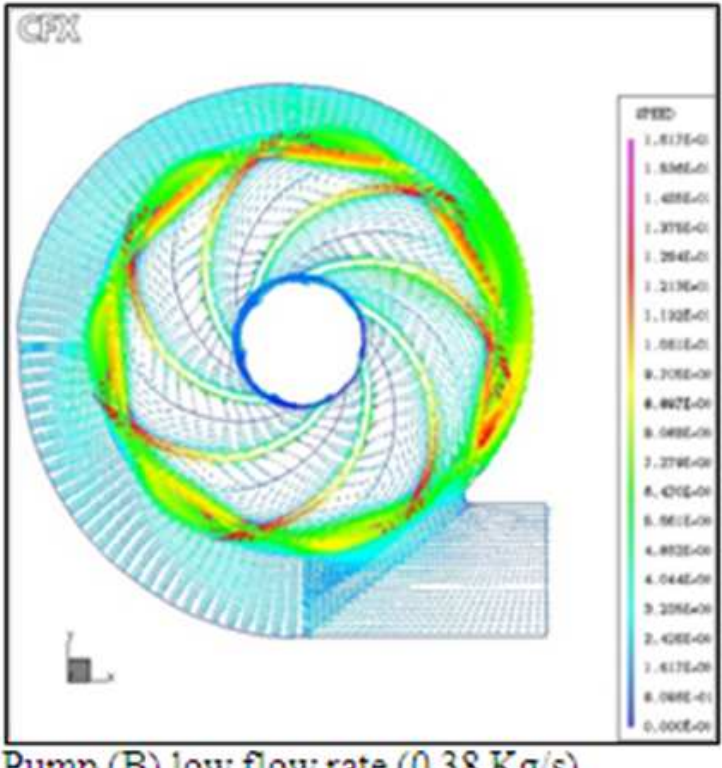

Pump (B) low flow rate $(0.38 \mathrm{Kg} / \mathrm{s})$

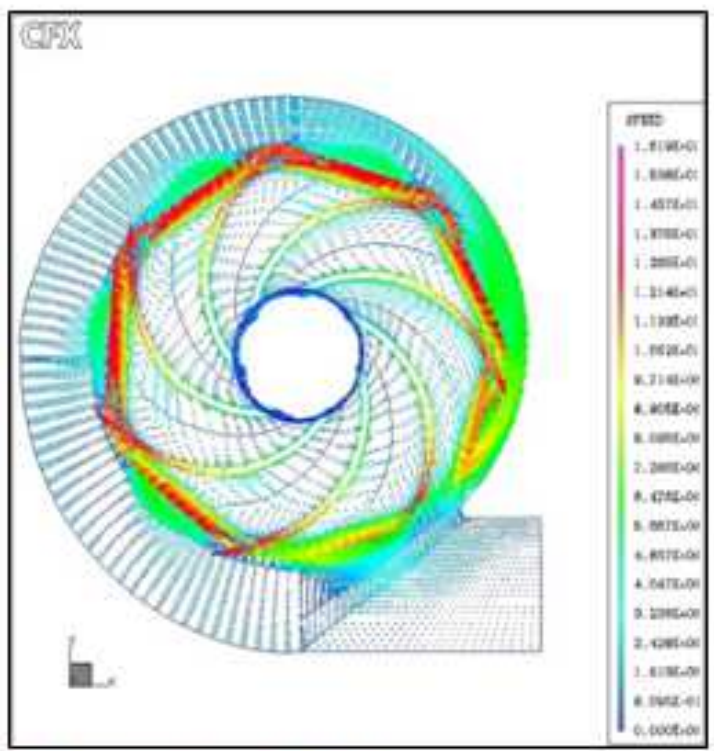

Pump (B) zero flow rate

Fig 5. Velocity vectors at midspan for both pumps.

The computations were performed in a rotating frame in impeller and in fixed frame in the diffuser and volute. The velocity field for both frames is presented. Relative velocity increases gradually along stream wise direction within the impeller passage. As the flow enters the impeller eye, it is diverted to the blade-to-blade passage; the flow along the blade is not symmetric and hence the separation of flow takes place in some passages near the pressure side of blades. Figure 5 shows the steady state velocity field inside impeller and vaneless diffuser with volute for four different flow rates at midspan section. Examining these figures, it is found that:

- For high flow rate for both pumps, Fig. 5-a, due to high velocity inside the pump there is no separation predicted in the plane at midspan, because the high momentum of the flow entrains the separation region. That is why the separation disappears for the high flow rate.

- At medium flow rate, Fig. 5-b, separation occurs in some positions in the passages because of the decreases the flow momentum.

- At low flow rate, Fig. 5-c, for both pumps, a massive separation zone is predicted at some positions in the passages.

- At zero flow rate, Fig. 5-d, a highly massive separation is predicted for all passages except at the passage facing the tongue region because the area between the impeller exit and the tongue decreases. This causes the velocity to increase and the pressure to decrease in the face of this passage. 
- -For zero flow rate, the vortex will be increased at impeller blade-to-blade passage due to high increase in pressure at vaneless diffuser and volute. The increase of pressure at that region causes back flow to the impeller passage that causes high losses due to vortex. The wake can now be identified as a slight perturbation affecting the direction of the velocity vectors close to the blade. It should be mentioned that, during the operation of both pumps it was noted that the noise level increases with decreasing the flow rate and is maximum at zero flow rate. This is due to increase of the vortex at the impeller blade-to-blade passage as explained in the above observation, and show that the jet-wake flow pattern is a source of noise generation near to blades trailing edge and it induces periodic pressure fluctuations on the blades surface.

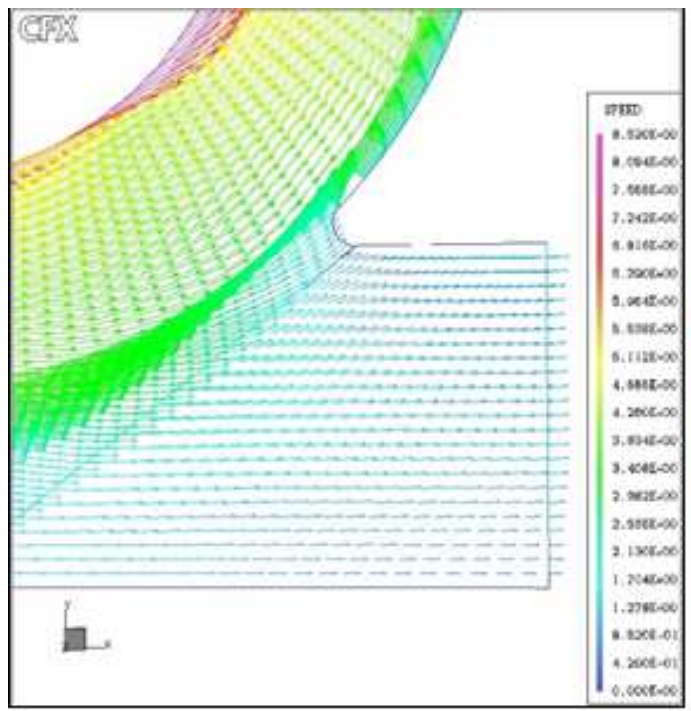

a-Pump (A) high flow rate $(0.78 \mathrm{Kg} / \mathrm{s})$

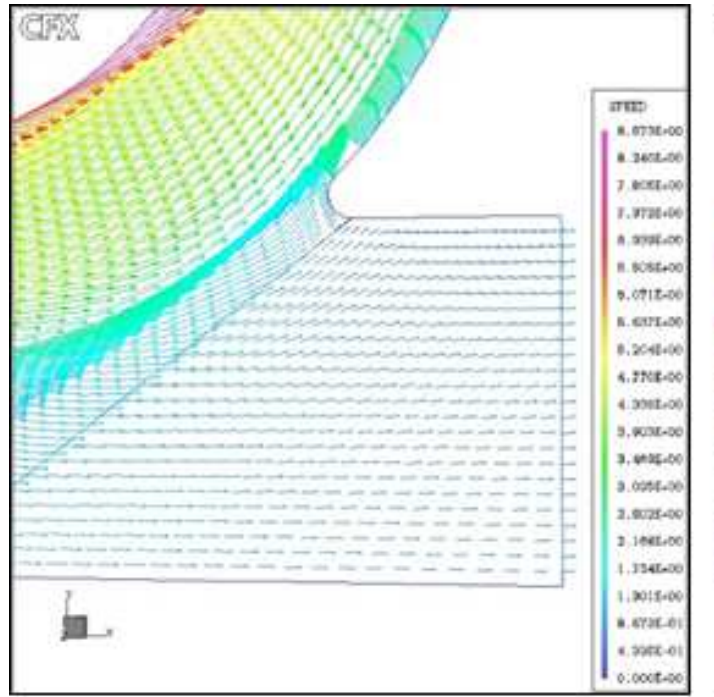

b-Pump (A) medium flow rate $(0.52 \mathrm{Kg} / \mathrm{s})$
- All figures show that the flow is more uniform at the vaneless diffuser of pump (A) because its vaneless diffuser is longer and the relative velocity value at exit from impeller is smaller compared with pump (B). The difference in pressure value between the two pumps can affect in the velocity distribution in the pumps.

\subsection{Velocity Vectors at the Tongue Section}

The major losses occurring in the pump are losses due to separation of the flow at the blade leading edge and at the tongue, wall friction losses and three-dimensional viscous flow in the volute. These losses have an important influence on the pressure rise in the pump even at optimum mass flow. Figure 6 shows the velocity vectors at tongue region at the four different flow rates.

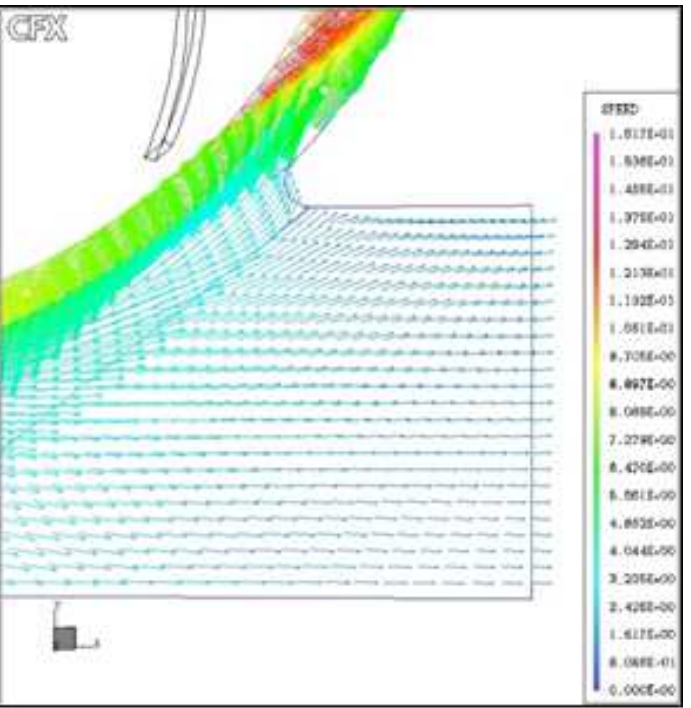

Pump (B) high flow rate $(1.0345 \mathrm{Kg} / \mathrm{s}$

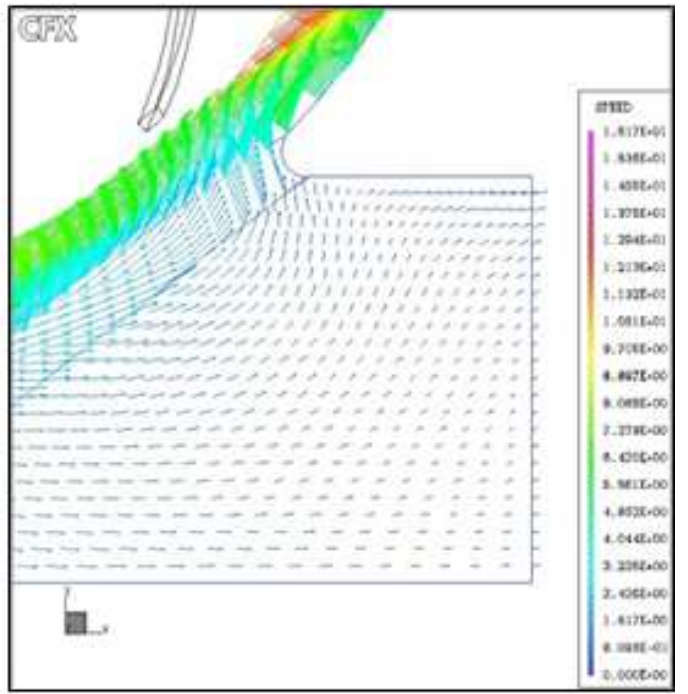

Pump (B) medium flow rate $(0.67 \mathrm{Kg} / \mathrm{s})$ 


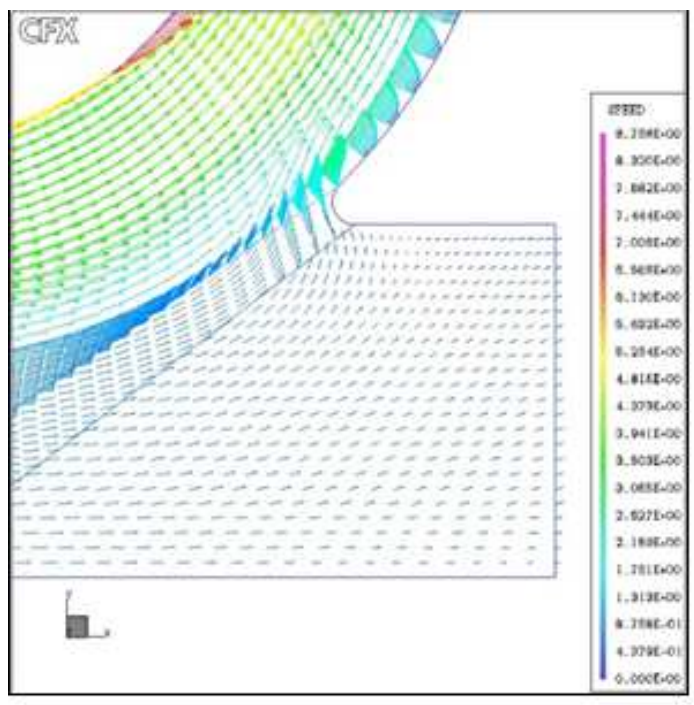

c-Pump (A) low flow rate $(0.24 \mathrm{Kg} \mathrm{s})$

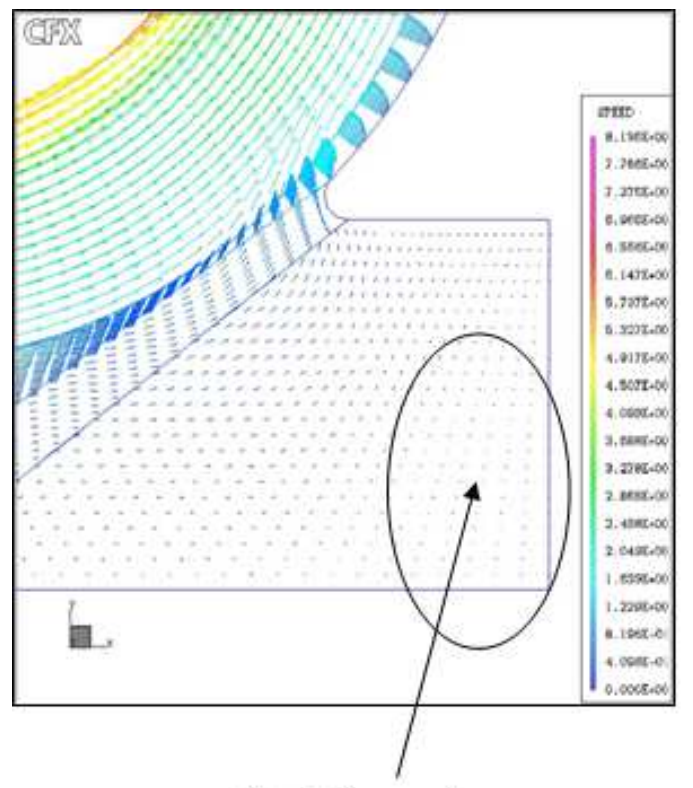

Back flow region

d-Pump (A) zero flow rate

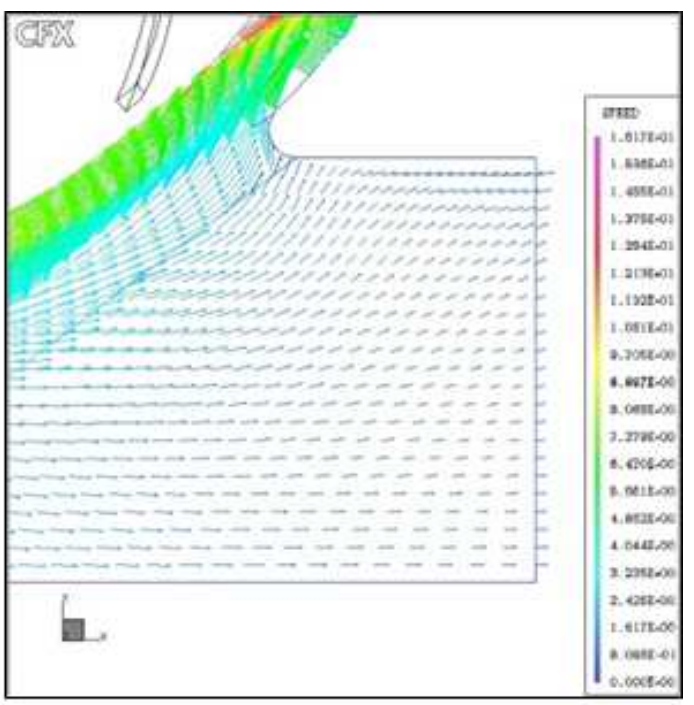

Pump (B) low flow rate $(0.38 \mathrm{Kg} / \mathrm{s})$

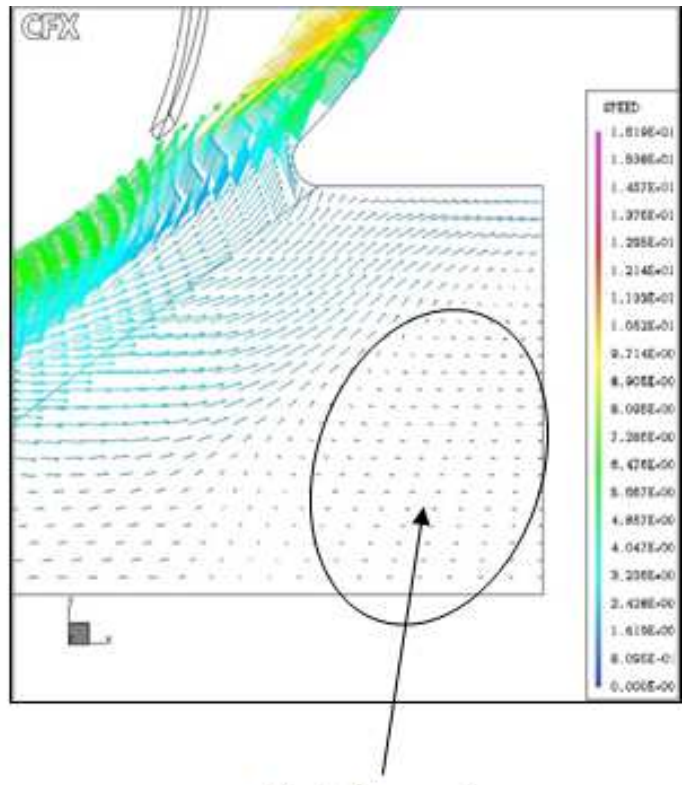

Backflow region

Pump (B) zero flow rate

Fig 6. Velocity vectors at tongue section for both pumps.

Examining Fig.6, it is found that:

- For both pumps the back flow that is reentering the tongue passage (the passage between the impeller exit and the tongue) increases with decreasing the outlet pump flow rate or, so that at zero flow rate the back flow is maximum. The velocity at the tongue section increases with decreasing the outlet pump flow rate.

- $\quad$ The back flow at the tongue passage for pump (B) is less than that at pump (A) because the cross section area between the impeller exit and tongue is smaller than pump (A), as the vaneless space for pump (B) is smaller compared with pump (A).

- At zero flow rate for both pumps the vortex occurs at the volute exit, the flow is blocked and the tongue region as shown in Fig. 6.

\subsection{Unsteady Pressure Fluctuations near the Tongue}

As an illustration, a monitoring point located $0.8 \mathrm{~cm}$ far from the tongue in the radial direction is selected to show the pressure fluctuations near the tongue. The combined effect of gap and flow rate on pressure fluctuations inside both pumps for the previous different flow rates is shown in Fig. 7. A typical fluctuation time history for one shaft revolution time, $21.6 \mathrm{~ms}$ is shown, where the local pressure at the monitoring point divided by the corresponding exit pressure for the four flow rate conditions. Comparing figures 7-a and 7-b, the pump B gives higher pressure fluctuations than pump A due to the smaller gap between the impeller and the volute tongue. 


\subsection{Turbulent Kinetic Energy}

It would be interesting also to show some samples of the instantaneous turbulent kinetic energy (TKE) for both pumps at midspan. Figure 8 shows the instantaneous TKE at high, medium, low and zero flow rates. The figure shows the asymmetry of the contours is very clear at the high flow rate this unsymmetrical distribution is attenuated by decreasing the flow rate until reaching the zero flow rate that show almost symmetrical distribution of the TKE. This is may be because the long length of the vaneless diffuser. The average value of the four cases is about is about $1 \mathrm{~J} / \mathrm{Kg}$.

For the pump B, Fig. 9 shows the same TKE distribution for the four values of the flow rates at midspan. The

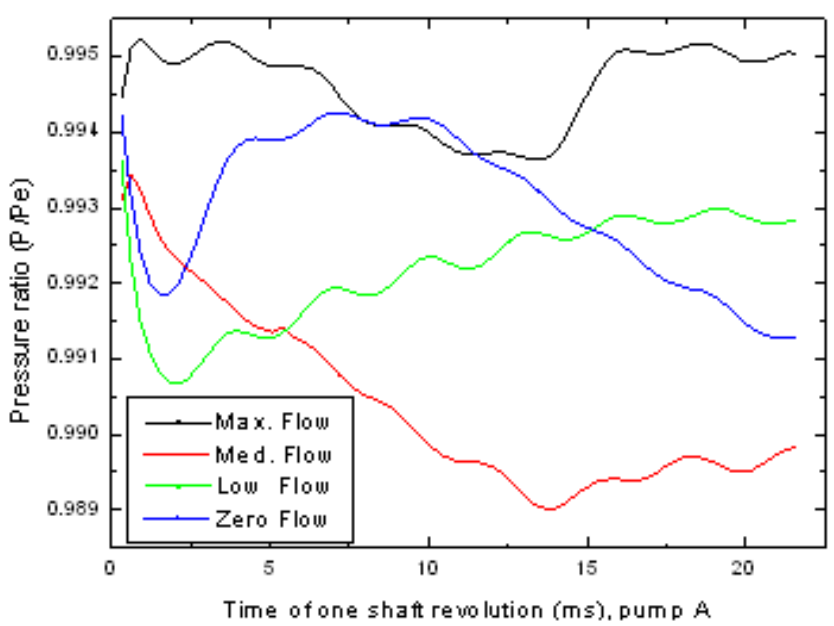

distribution is different for the four values of the flow rates. The shorter diffuser length makes the flow asymmetry for all flow rates. It is also noted that a higher level of the TKE (average value of $2 \mathrm{~J} / \mathrm{Kg}$ ) can be obtained for all cases.

\subsection{Comparison between Numerical and Experimental Performances}

Figure 10 shows the numerical and experimental characteristics curves for both pumps. The numerically calculated head follows the trend very well as compared to the experimental one. However, it could not match exactly the numerical head one-to-one with head experimental data.

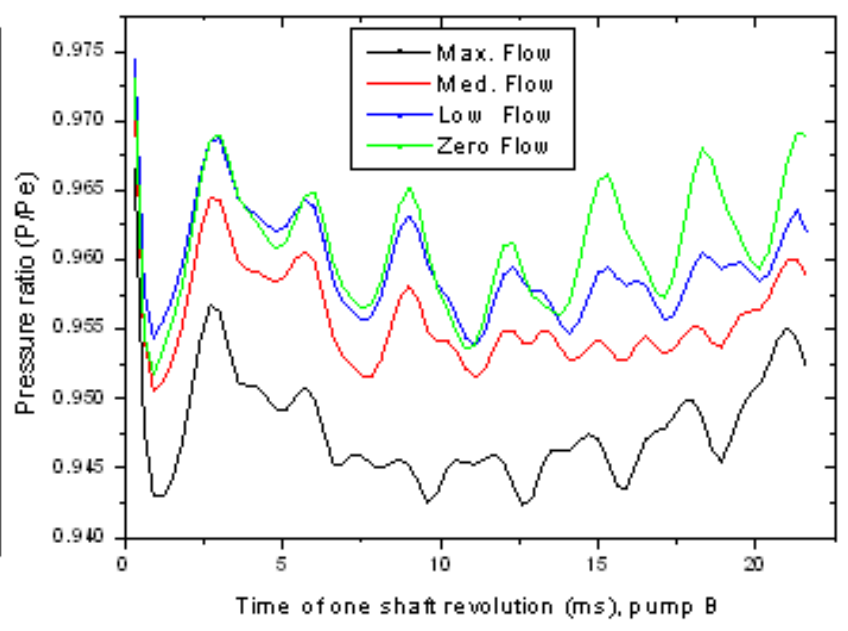

Fig 7. Dimensionless pressure near the tongue.

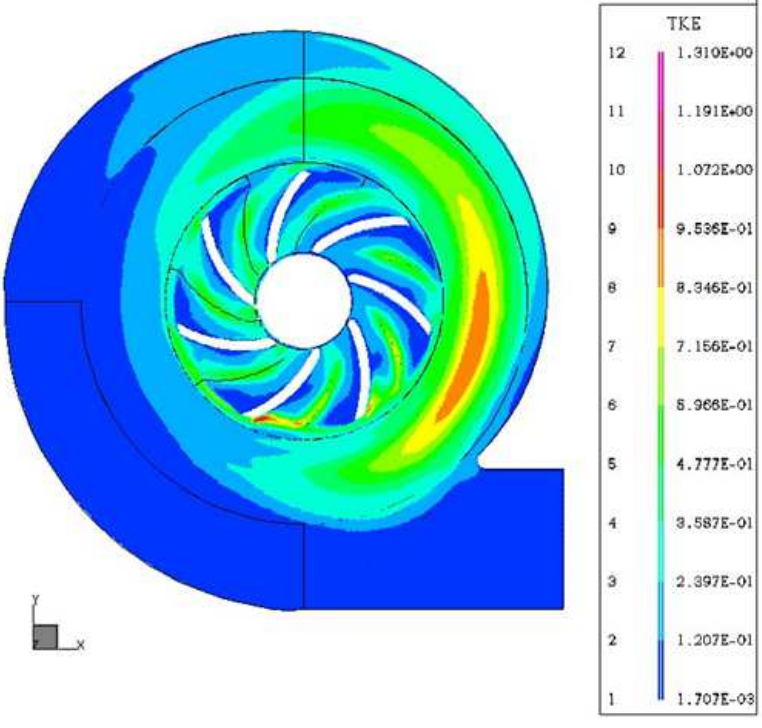

Pump (A)high flow rate $(0.78 \mathrm{Kg} / \mathrm{s})$

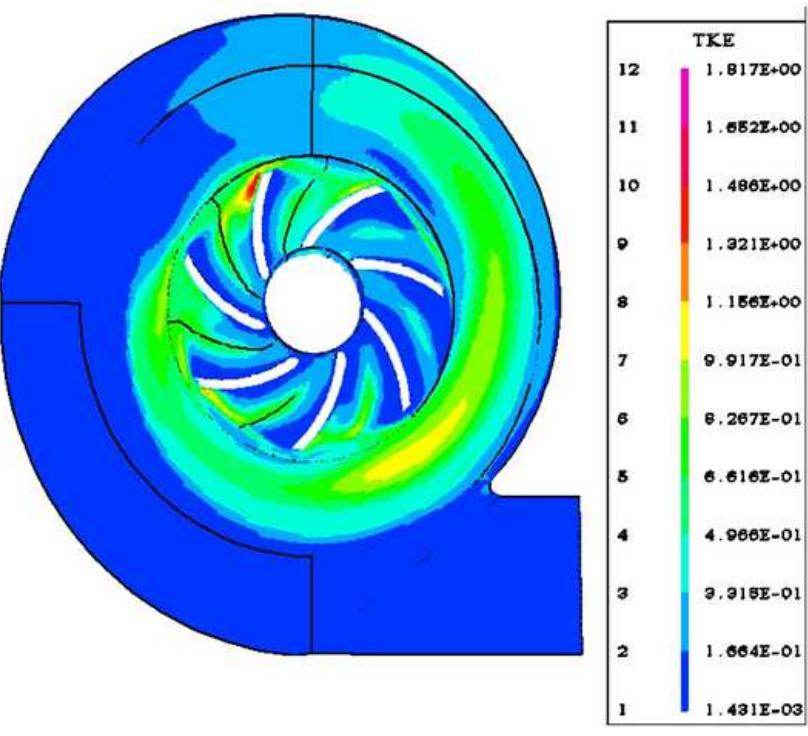

Pump (A)medium flow rate $(0.52 \mathrm{Kg} / \mathrm{s})$ 


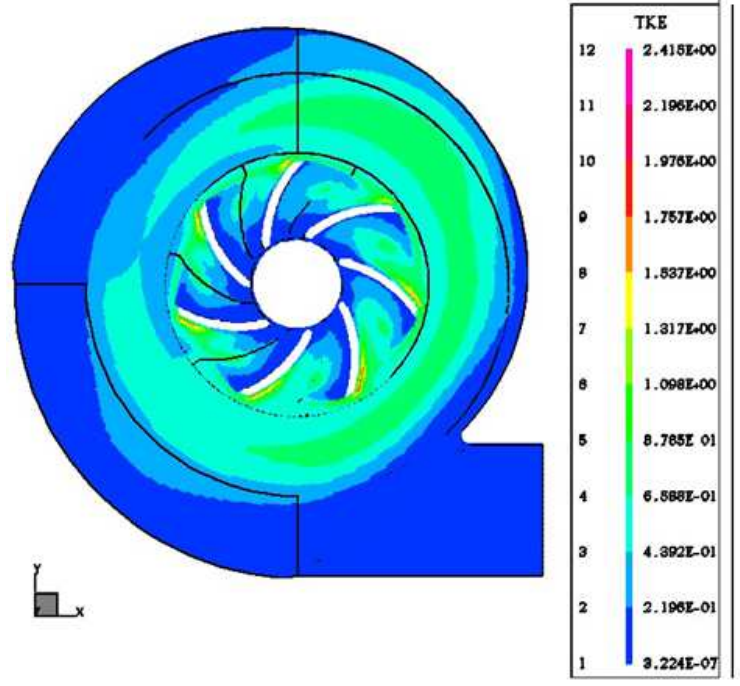

Pump (A)low flow rate $(0.24 \mathrm{Kg} / \mathrm{s})$

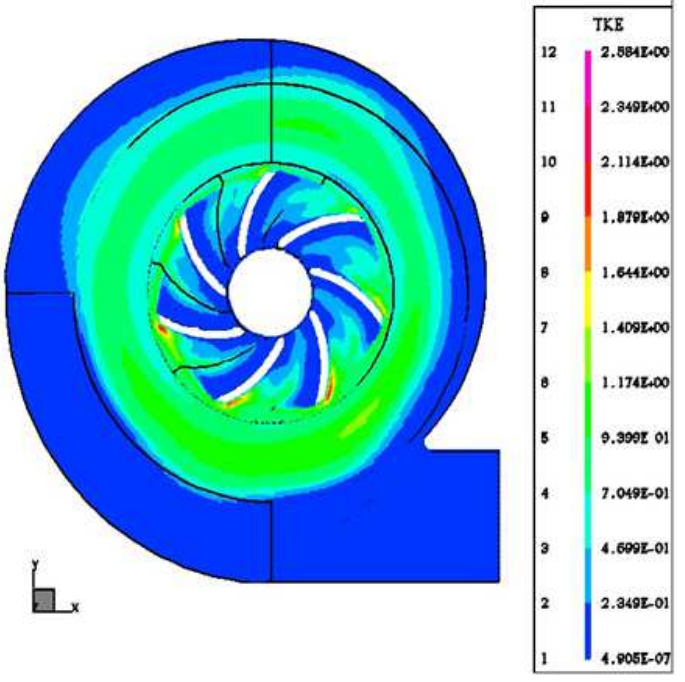

Pump (A) zero flow rate

Fig 8. Turbulent kinetic energy contours for pump A.

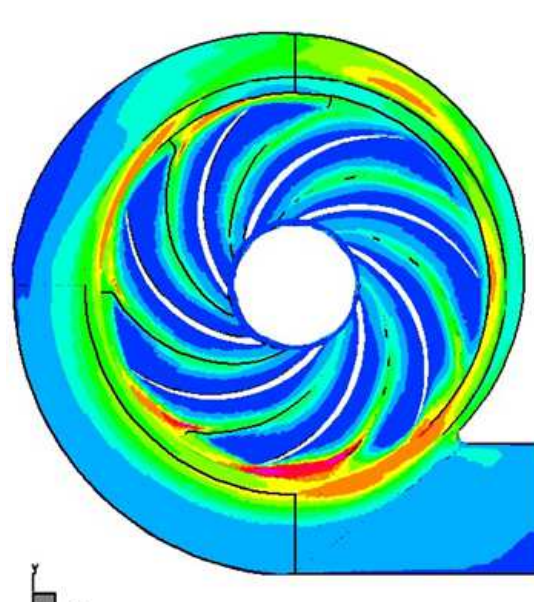

G

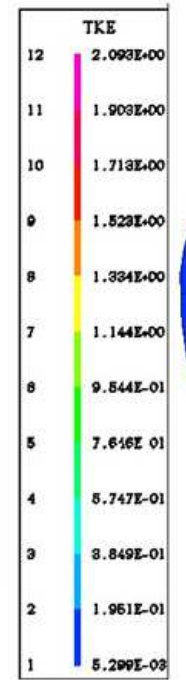

Pump (B)high flow rate $(1.034 \mathrm{Kg} / \mathrm{s})$

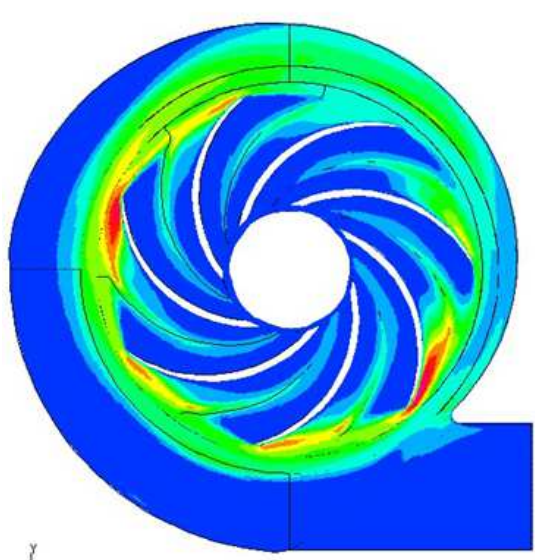

$\square \times$

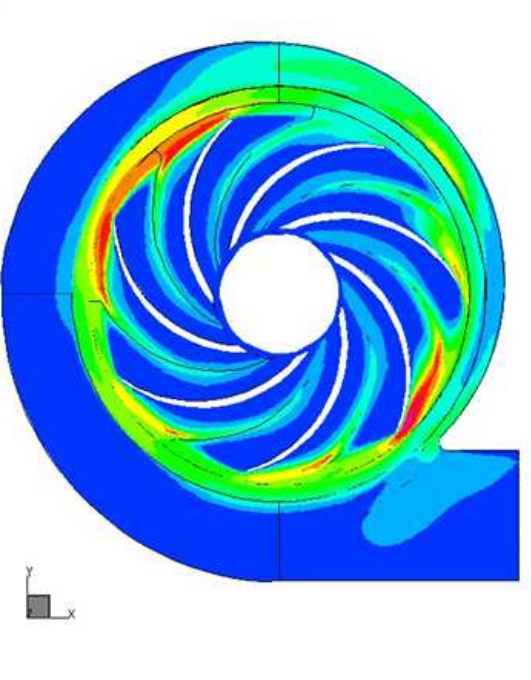

Pump (B)medium flow rate $(0.67 \mathrm{Kg} / \mathrm{s})$

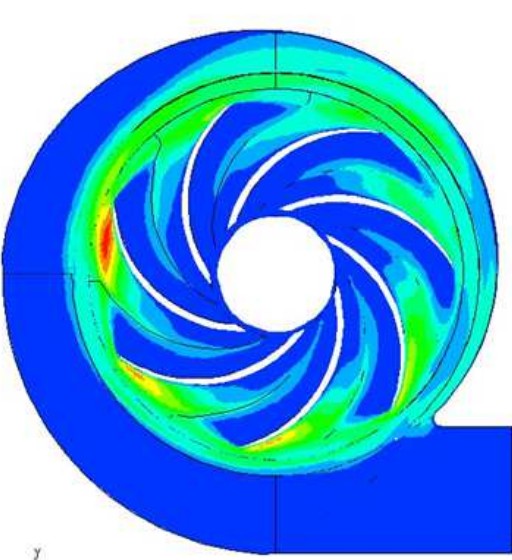

$\square$.

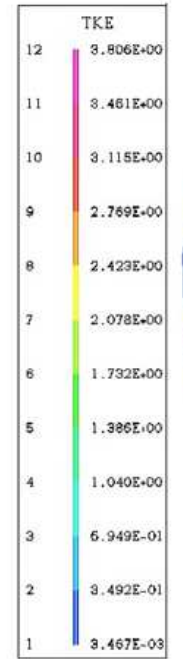

Pump (B) low flow rate $(0.38 \mathrm{Kg} / \mathrm{s})$
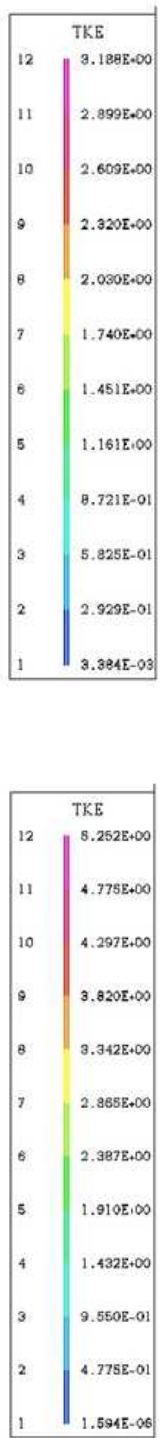

Pump (B) zero flow rate

Fig 9. Turbulent kinetic energy contours for pump $B$. 
The numerical head for both pumps A and B is higher than the experimental head at low flow rate and smaller at the maximum flow rate. The best agreement between the numerical and experimental results is observed at the medium flow rate.

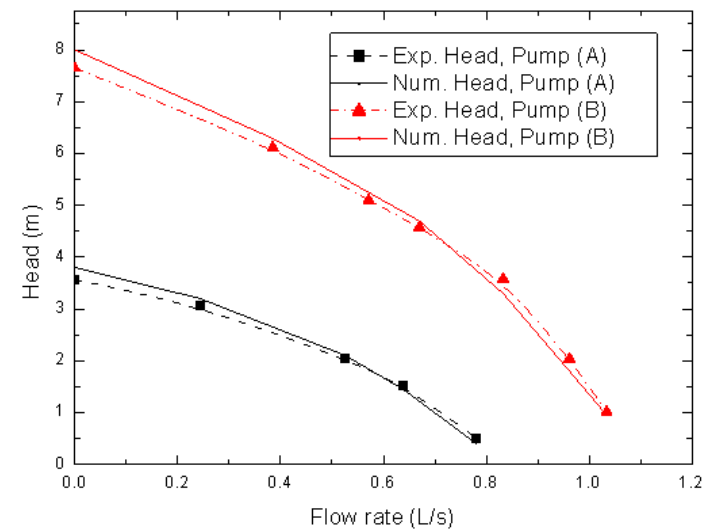

Fig 10. Experimental and numerical characteristics curves for both pumps.

\section{Conclusions}

The goal of this work as given at the outset is to provide information of the steady and unsteady flow in the centrifugal pump which can be used in understanding and improving its performance. In this work the experimental and numerical study carried out on two pumps with different impeller diameters at different flow rate at 2800 rpm. There are some conclusions that can be drawn from the study results presented in this work.

1- The experimental work presented the head-flow curve for the both pumps; it was found that the head of pump (B) is higher than that for pump (A).

2- For both pumps, the pressure developed inside the impeller is not uniform, and increases gradually from suction to the outlet duct of the pump. The pressure distribution for small impeller pump is more uniform in the volute part than the bigger impeller pump and the area of high pressure region in the volute is larger for small impeller pump. The area of the high pressure region in the volute for small impeller pump increases with decreasing the flow rate, but this is not the case for the bigger impeller pump.

3- At high flow rate, for both pumps, there is no separation predicted in the plane at midspan, and the separation appears when the flow rate decreases while a highly massive separation is predicted at zero flow rate for both pumps. At zero flow rate, the only passage that has no separation is the passage facing the tongue region because the area between the impeller exit and the tongue is relatively small. This cause the velocity to increase and the pressure to decrease in the face of this passage.

4- The back flow reentering the tongue passage increases with decreasing the outlet pump flow rate. At zero flow rate the back flow is maximum, and the velocity at that section increases with decreasing the outlet pump flow rate. The back flow at tongue passage is different for each pump due to the cross section area between the impeller exit and tongue is not equal.

5- The pump B gives more pressure fluctuations at a monitoring point near the tongue than pump A due to the smaller gap between the impeller and the tongue.

6- The pump B gives more unsymmetric turbulent kinetic energy that the pump A.

\section{References}

[1] Binder, R. C., and Knapp, R. T., 1936, "Experimental Determination of the Flow Characteristics in the Volutes of Centrifugal Pumps," Trans. ASME, 58, No. 8, p. 659.

[2] Acosta, A. J., and Bowerman, R. D., 1957, “An Experimental Study of Centrifugal Pump Impellers," Trans. ASME, 79, pp. 1821-1831.

[3] Stepanoff, A. J., 1957, Centrifugal and Axial Flow Pumps, Wiley, NY.

[4] Agostinelli, A., Nobles, D., and Mockridge, C. R., 1960, "An Experimental Investigation of Radial Thrust in Centrifugal Pumps,” ASME J. Eng. Power, 80, pp. 120-126.

[5] Biheller, H. J., 1965, "Radial Forces on the Impeller of Centrifugal Pumps with Volute, Semivolute, and Fully Concentric Casings,” ASME J. Eng. Power, 85, pp. 319-323.

[6] Hergt, P., and Krieger, P. 1972, "Radial Forces and Moments Acting on the Impeller of Volute Casing Pumps," Proceedings of the Fourth Conference of Fluid Machinery, Budapest, pp. 599-619.

[7] Kanki, H., Kawata, Y., and Kawatani, T., 1981, "Experimental Research on the Hydraulic Excitation Force on the Pump Shaft," Proceedings, ASME Design Engineering Technical Conf., 81-DET-71, Sept., Hartford, CT.

[8] Chamieh, D. S., Acosta, A. J., Brennen, C. E., Caughey, T. K., and Franz, R., 1985, "Experimental Measurements of Hydrodynamic Radial Forces and Stiffness Matrices for a Centrifugal Pump Impeller," ASME J. Fluids Eng., 107, pp. 307-315.

[9] De Ojeda, W., Flack, R. D., and Miner, S. M., 1995, “Laser Velocimetry Measurements in a Double Volute Centrifugal Pump,” Int. J. Rotat. Mach., 1, Nos. 3-4, pp. 199-214.

[10] Inoue, M., and Cumpsty, N. A., 1984, "Experimental Study of Centrifugal Impeller Discharge Flow in Vaneless and Vaned Diffusers,"ASME J. Eng. Gas Turbines Power, 106, pp. 455-467.

[11] Sideris, M. T., and Van den Braembussche, R. A., 1987, "Influence of a Circumferential Exit Pressure Distortion on the Flow in an Impeller and Diffuser," ASME J. Turbomach., 109 , pp. 48-54.

[12] Arndt, N., Acosta, A. J., Brennen, C. E., and Caughey, T. K., 1989, "Rotor- Stator Interaction in a Diffuser Pump," ASME J. Turbomach., 111, pp. 213-221. 
[13] Arndt, N., Acosta, A. J., Brennen, C. E., and Caughey, T. K., 1990, "Experimental Investigation of Rotor-Stator Interaction in a Centrifugal Pump With Several Vaned Diffusers," ASME J. Turbomach., 112, pp. 98-108.

[14] Meakhail T., Seung O Park, “ A Study of Impeller-DiffuserVolute Interaction in a Centrifugal Fan" ASME Journal of Turbomachinery, vol.127, no. 1, 2005, pp 84-90.

[15] Kaupert, K. A., and Staubli, T., 1999, "The Unsteady Pressure Field in a High Specific Speed Centrifugal Pump Impeller. Part I: Influence of the Volute," ASME J. Fluids Eng., 121, pp. 621-626.

[16] Ramesha., Prema K., Sharma, Raghuprasad, Madhusudan M. " Simulation Of Three Dimensional Flows In Hydraulic Pumps" International journal of Advanced Scientific and Technical Research Issue 1 vol. 1 October, 2011, pp. 62-68.
[17] Bao-ling C., Yong-gang L. and Ying-zi J. "Numerical Simulation of Flow in Centrifugal Pump with Complex Impeller" Journal of Thermal Science, vol. 20, No. 1, 2011, pp 47-52.

[18] Raúl B. , Jorge P. and Eduardo B. "Numerical Analysis of the Unsteady Flow in the Near-Tongue Region in a VoluteType Centrifugal Pump for Different Operating Points" Computers \& Fluids Journal vol. 39,2010, pp. 859-870.

[19] ASC, 1999, "CFX-TASCflow Documentation Version 2.9.0," Advanced Scientific Computing, Ltd., Waterloo, Ontario, Canada

[20] ASC, 1999, “CFX-Turbogrid Documentation Version 1.4," Advanced Scientific Computing, Ltd., Waterloo, Ontario, Canada. 